\title{
Predictions of Academic Performance in Graduate and Professional School
}

\author{
Pang-chieh Lin and Lloyd G. Humphreys \\ University of Illinois, Urbana-Champaign
}

Using a model followed in earlier research, correlations were computed between undergraduate and graduate grade-point averages as well as between these and standard graduate and professional school tests. Approximately 1200 law school students constituted a professional school sample and another 1200 students in mathematics, physics, and chemistry constituted a graduate school sample. Earlier findings were replicated. In addition, it is shown that both graduate and professional school grades form simplex matrices and that early grades are more highly predictable from aptitude tests than later grades. There is evidence for a single simplex matrix extending through the four undergraduate and three post-graduate years only in the law school sample. There are two separate simplex matrices for the two levels in the graduate school sample. Correlations between test scores and undergraduate grades are biased to very low values in the professional school sample by a compensatory selection system, but both aptitude and achievement tests are clearly more highly correlated with freshman than with senior grades in the graduate school sample. In this sample, however, the advanced test in the discipline is more highly correlated with first year graduate grades than with senior grades.

These data suggest that the first year in a new academic learning situation represents a greater intellectual challenge than subsequent years.

In a series of papers (Humphreys, 1960, 1968,

APPLIED PSYCHOLOGICAL MEASUREMENT

Vol. 1. No. 2 Spring 1977 pp. 249-257

(c) Copyright 1977 West Publishing Co. and Humphreys and Taber, 1973) data have been presented concerning instability in intellectual and academic performance of undergraduate college students. These studies have shown that the intercorrelations of independently computed grade-point averages form a quasi-simplex matrix, that the predictions of these averages from freshman entrance information gradually decrease in accuracy from the freshman year to the senior year, and that the postdiction correlations (criterion measure obtained prior to the administration of measures ordinarily used predictively) with Graduate Record Examination (GRE) aptitude scores obtained during the senior year also show progressively lower correlations with grades from the freshman to the senior year. While the Advanced Test validities do not drop during the sophomore and junior years as the aptitude test validities do, the correlations with freshman grades are still higher than those with senior grades.

On the basis of the findings with the broad aptitude tests, senior grades are seemingly less intellectual than freshman grades. Furthermore, senior grades do not reflect as accurately individual differences in specialized knowledge in the major area as freshman, sophomore, and junior grades predict those differences. By infer- 
ence, high school rank in class and college entrance test scores would be more highly correlated with the advanced test scores than with senior grades. This should be true both for obtained correlations and correlations corrected for attenuation.

There are two possible explantions for the simplex matrix of intercorrelations: "the factorial nature of semester grades is gradually changing" and "people are gradually changing." There appears to be evidence for both explanations in the research reported to date. Similar validity gradients for highly similar predictors and postdictors suggest strongly that the criterion is changing. To support a sole explanation that people are changing, the predictive and postdictive gradients should have approached a mirror image relationship. On the other hand, the relatively high level of correlations of freshman, sophomore, and junior grades with the advanced test indicate that people are changing as well.' A possible interpretation is that consistent individual differences in a trait narrower than those measured by the Verbal and Quantitative tests of the GRE are developing during the undergraduate years.

The Verbal and Quantitative aptitude tests are the most widely used tests for purposes of graduate student selection. The GRE Advanced Tests are used less frequently. It is disconcerting, to say the least, to find that these tests are more highly correlated with freshman than with senior grades. Thus, on practical grounds, it is very important to follow up the research done to date with data from the post baccalaureate years. Such data are also important theoretically. If senior grades are the best predictors of first year graduate or professional school grades, if first year grades are the best predictors of second year grades, and so forth, up the grad-

'Broad abilities as measured by typical academic aptitude tests do change a little during the undergraduate years. Lunneborg and Lunneborg (1970) report test-retest correlations over a four year period. Lin (1976) also reports similar correlations. It is probable that correlations corrected for attenuation of about .9 represent the degree of stability of these abilities. uate school ladder, traditional conceptions of the role of intelligence in advanced academic performance will have to be modified.

\section{Procedures}

The first decision made was to study the problem in a professional school of law and in the graduate departments of mathematics, physics, and chemistry. The former selection was made because law students are not acquiring the subject matter of law during their undergraduate years, whereas learning in the three academic disciplines is cumulative, with specialization starting during the undergraduate period. Selection of three departments was a compromise between the need for a large $N$ and the need not to extend the sample over an unduly long time period, with its attendant changes in grading practices, admissions standards, etc. The particular graduate departments were selected because they attract somewhat similar students, have large numbers of graduate students, and have faculties that have more or less maintained reliable and valid standards of undergraduate and graduate grading. This last criterion barred a large number of departments from consideration.

The samples selected were constituted as follows: 1230 law school students entering from 1968 through 1972; 519 mathematics students entering from 1968 through 1972; 354 physics students and 325 chemistry students entering from 1970 through 1972. Problems arising from different records disposition and storage practices restricted the number of years studied for the latter two groups. All samples were from a single, large land-grant university which draws professional and graduate students from large numbers of widely scattered undergraduate institutions. For purposes of this research, however, foreign students and special admissions students were excluded.

No new information was requested from the members of these samples. Records were used to obtain as much of the following information as possible: undergraduate grades. GRE scores or 
Law School Aptitude Test (LSAT) scores, and graduate or professional school grades. At least two semesters of graduate or professional school grades were available for all members of the several samples, and a cutoff of six semesters, excluding summer sessions, was imposed on the earliest classes.

Because undergraduate institutions differ in their academic calendars, annual undergraduate grade-point averages (GPAs) were computed in place of the semester averages used in previous research. As in the earlier research, each year's GPA was computed independently. Semester grade-point averages were computed independently for each semester that the student was in post-baccalaureate residence. Finally, for correlational purposes the data were pooled by year in graduate or professional school. Entrance date was disregarded.

\section{Results}

Table 1 presents the intercorrelations of the independently computed GPAs for four undergraduate years and six graduate semesters for students in the three graduate departments. Since there is need for small sampling errors, which are none too small even when based on 1000 cases, only the composite table of withingroup correlations is presented. This removes any temptation for either the authors or readers to attempt interpretations of small differences in patterns of intercorrelations that are well within the variability expected on the basis of sampling error.

The simplex matrix of intercorrelations is clearly apparent within the undergraduate years and, separately, within the six graduate semesters. The former finding replicates earlier research in an important new way. These intercorrelations are based on students whose grades were accumulated in literally dozens of undergraduate institutions. Students who were also undergraduates in the present graduate institution represent only a very small proportion of the

$$
\text { Table } 1
$$

Intercorrelations* of Grade-point Averages in Four Undergraduate Years and Six Graduate Semesters for Students in Physics, Chemistry, and Mathematics

\begin{tabular}{|c|c|c|c|c|c|c|c|c|c|c|c|}
\hline Time Period & & 1 & 2 & 3 & 4 & 5 & 6 & 7 & 8 & 9 & 10 \\
\hline \multicolumn{12}{|l|}{ Undergraduate } \\
\hline Year 1 & 1 & .521 & .662 & .496 & .383 & .260 & .238 & .229 & .229 & .083 & .117 \\
\hline Year 2 & 2 & 1047 & .510 & .653 & .499 & .283 & .253 & .226 & .204 & .038 & .078 \\
\hline Year 3 & 3 & 1042 & 1068 & .456 & .565 & .255 & .255 & .269 & .191 & .078 & .070 \\
\hline Year 4 & 4 & 916 & 938 & 944 & .479 & .282 & .274 & .250 & .173 & .018 & .017 \\
\hline \multicolumn{12}{|l|}{ Graduate } \\
\hline Semester 1 & 5 & 1046 & 1072 & 1074 & 944 & .449 & .445 & .332 & .276 & .163 & .142 \\
\hline Semester 2 & 6 & 1016 & 1042 & 1044 & 917 & 1162 & .452 & .469 & .301 & .187 & .271 \\
\hline Semester 3 & 7 & 775 & 794 & 795 & 709 & 899 & 899 & .465 & .370 & .213 & .179 \\
\hline Semester 4 & 8 & 638 & 653 & 654 & 593 & 739 & 739 & 739 & .467 & .365 & .276 \\
\hline Semester 5 & 9 & 401 & 407 & 408 & 381 & 470 & 470 & 470 & 470 & .404 & .369 \\
\hline Semester 6 & 10 & 261 & 262 & 263 & 250 & 302 & 302 & 302 & 302 & 302 & .367 \\
\hline
\end{tabular}


total. As compared to entering freshmen, graduate students represent a restricted range of ability, but the overall level of the undergraduate grade intercorrelations is very similar to those reported earlier. This may be taken as evidence supporting a follow-up publication based on the earlier data (Humphreys, Levy, and Taber, 1973). Undergraduates of high academic promise were shown to be more stable in academic performance and hence more predictable than those of relatively low academic promise.

During the graduate semesters there is evidence for decreasing variability of GPAs which is accompanied by a reduction in the size of correlations between adjacent semesters. This picture is complicated, however, by the reduction in the size of the $N$ from year to year during this period. In any event, good first-year graduate students are not identical with good third-year students, just as good freshmen are not identical with good seniors, as measured by academic grades.

The cross-correlations between undergrad- uate and graduate grades represent an unexpected finding. The reduced level of correlations is not a problem, since this reduction can be explained by the heterogeneity of standards of admission and grading of the undergraduate institutions represented. Note that this heterogeneity does not affect the undergraduate intercorrelations where, except for transfer students, it is constant from year to year. The surprise arises from the almost constant level of predictions of graduate grades from each of the four years of the undergraduate record. This finding indicates that there is not a continuous learning experience extending from the freshman year to the third graduate year. Instead, the transition from undergraduate college to graduate school represents an abrupt break, with a new simplex matrix starting with the first graduate semester. There is a common core or common factor running through the four undergraduate and at least the first two graduate years on which some as-yet-unidentified processes of gradual change are superimposed. While this common core

Table 2

Intercorrelations: of Crade-point Averages in Four Undergraduate Years and Six Graduate Semesters for Students in Law Schocl

\begin{tabular}{|c|c|c|c|c|c|c|c|c|c|c|c|}
\hline Time Perioci & & 1 & 2 & 3 & 4 & 5 & 6 & 7 & 8 & 9 & 10 \\
\hline \multicolumn{12}{|l|}{ Undergraduate } \\
\hline Year 1 & 1 & .561 & .550 & .445 & .429 & .229 & .268 & .212 & .250 & .147 & .090 \\
\hline Year 2 & 2 & 1159 & .532 & .601 & .492 & $.27 \hat{0}$ & .288 & .243 & .232 & .143 & .086 \\
\hline Year 3 & 3 & 1155 & 1163 & .497 & .646 & .279 & .317 & .252 & .279 & .219 & .141 \\
\hline Year 4 & 4 & 1116 & 1123 & 1126 & .488 & .307 & .331 & .274 & .282 & .236 & .266 \\
\hline \multicolumn{12}{|l|}{ Graciuate } \\
\hline Semester 1 & 5 & 1162 & 1168 & 1169 & 1131 & .479 & .676 & .565 & .561 & .469 & .432 \\
\hline Semester 2 & 6 & 1161 & 1167 & 1168 & 1130 & 1230 & .463 & .594 & .593 & .483 & .476 \\
\hline Semester 3 & 7 & 999 & 1004 & 1006 & 980 & 1063 & 1062 & .538 & .608 & .534 & .562 \\
\hline Semester 4 & 8 & 996 & 1001 & 1003 & 977 & 1059 & 1058 & 1057 & .522 & .555 & .488 \\
\hline Semester 5 & 9 & 826 & 830 & 833 & 811 & 880 & 879 & 878 & 876 & .471 & .528 \\
\hline Semester 6 & 10 & 709 & 714 & 717 & 703 & 754 & 753 & 752 & 750 & 753 & .483 \\
\hline
\end{tabular}


seemingly represents only a small percentage of common variance, the correlations are attenuated both by measurement error and by the lack of a common metric.

Table 2 represents comparable data for students in law school. The simplex matrices within the undergraduate years and the professional school semesters are quite similar, although the correlations involving the second and third professional school years were more reliably determined. The post-baccalaureate simplex matrix generalizes to a learning situation that is quite different in many ways from the one in graduate school.

The cross-correlations present a different picture. There is a fairly consistent tendency for the rank-order from high to low of the four undergraduate years in the prediction of professional school grades to be senior, junior, sophomore, and freshman grades. The only reversals are between freshman and sophomore grades in the last three semesters of professional school. If one looks only at the first semester of professional school and compares freshman and senior grade correlations, the difference between the correlations, on the assumption of independence, is significant at the .05 level. If one assumes a constant sample, which is very nearly an accurate assumption, and takes into account the degree of dependence between the predictors, the difference in correlations is significant at the .01 level. Furthermore, making a guess concerning the amount of attenuation introduced by lack of a common metric, one can conclude that for these students the simplex process continues without an appreciable break from the freshman year to the completion of the professional school experience. ${ }^{2}$

Earlier papers in this series also reported intercorrelations based on constant $N$ s, which represented an experimental way of controlling for possible differences in range of aptitude. Only

${ }^{2}$ An unpublished manuscript by Carlson and Werts (1975) contains data on a somewhat larger total sample, but one drawn from several different law schools, that do not support the present findings. No explanation for this discrepancy is currently available, but analyses are continuing. the data for the first two semesters in graduate school were based upon $N$ s large enough to make the results meaningful. These data are not in conflict with those in Table 1, but they do not add enough information to be worth reporting. However, an $N$ of 674 was available throughout the seven-year period for the law school students. These intercorrelations are presented in Table 3. There are no important changes from the relationships found in Table 2.

The three graduate departments did not require the submission of GRE scores in applications for admission, but such scores were submitted by almost half of the students. Correlations between the GRE tests and the independently-computed GPAs are presented in Table 4 for both maximum and constant samples.

The correlations between test scores and undergraduate grades replicate the findings of Humphreys and Taber (1973) within the limits of sampling error. All tests are more highly correlated with freshman than with senior grades. Even the advanced test in the present data shows correlations that drop off from the freshman to the sophomore year, in contrast to the earlier results, which showed a small increase over this time period. The earlier correlations, however, were based upon larger $N \mathrm{~s}$ and were thus more stable.

First-year graduate grades are best predicted from the tests administered during the senior year, followed in turn by second- and third-year grades. Thus the predictions of graduate performance from the GRE tests show the same gradient as predictions of undergraduate grades from high school rank in class and American College Testing Program scores. If it is legitimate to call the prediction of undergraduate grades "fleeting" (Humphreys, 1968), it is also legitimate to apply the same term to the predictions of six semesters of graduate grades.

Meaningful comparison of the size of the correlations of GRE tests with undergraduate and graduate grades is not possible. The more nearly common metric at the graduate level may be the sole reason why the Advanced Test shows a higher correlation with first-year graduate 
Table 3

Intercorrelations* of Grace-point Averages in Four Undergraduate Years and Six Graduate Semesters for Students in the College of Law

\begin{tabular}{|c|c|c|c|c|c|c|c|c|c|c|c|}
\hline Time Period & & 1 & 2 & 3 & 4 & 5 & 6 & 7 & 8 & 9 & 10 \\
\hline \multicolumn{12}{|l|}{ Undergracuate } \\
\hline Year 1 & 1 & .522 & .478 & .340 & .314 & .184 &. .280 & .178 & .190 & .139 & .089 \\
\hline Year 2 & 2 & & .481 & .492 & .393 & .222 & .213 & .207 & .162 & .157 & .080 \\
\hline Year 3 & 3 & & & .450 & .604 & .284 & .290 & .258 & .249 & .248 & .142 \\
\hline Year 4 & 4 & & & & .458 & .293 & .293 & .244 & .244 & .236 & .166 \\
\hline \multicolumn{12}{|l|}{ Graduate } \\
\hline Semester 1 & 5 & & & & & .483 & .676 & .544 & .553 & .462 & .419 \\
\hline Semester 2 & 6 & & & & & & .465 & .566 & .578 & .459 & .450 \\
\hline Semester 3 & 7 & & & & & & & .542 & .593 & .528 & .559 \\
\hline Semester 4 & 8 & & & & & & & & .526 & .539 & .467 \\
\hline Semester 5 & 9 & & & & & & & & & .466 & .514 \\
\hline Semester 6 & 10 & & & & & & & & & & .480 \\
\hline
\end{tabular}

\#II is 674 for each correlation. Standard deviations are in the ciagonal.

Table 4

Validities of the Three GRE Tests Computed in Two Different Ways

\begin{tabular}{|c|c|c|c|c|c|c|c|c|c|c|}
\hline \multirow{2}{*}{ Group \& Test } & \multicolumn{3}{|c|}{ Undergraduate } & Year & \multicolumn{3}{|c|}{ Graduate } & \multicolumn{2}{|c|}{ Semester } & \multirow[b]{2}{*}{6} \\
\hline & 1 & 2 & 3 & 4 & 1 & 2 & 3 & 4 & 5 & \\
\hline Total Sample & & & & & & & & & & \\
\hline Verbal & .174 & .013 & -.029 & .037 & .090 & .131 & .124 & -.026 & -.034 & -.034 \\
\hline II & $5 \pm 7$ & 535 & 532 & 442 & 555 & 544 & 409 & 335 & 183 & 114 \\
\hline Quantitative & .247 & .182 &.$\$ 26$ & .110 & .231 & .261 & .242 & .185 & .152 & .049 \\
\hline li & 516 & 534 & 531 & 441 & 554 & 543 & 408 & 334 & 182 & 113 \\
\hline Advanced & .240 & .214 & .163 & .132 & .363 & .330 & .240 & .175 & .062 & .012 \\
\hline 11 & 513 & 531 & 528 & 442 & 552 & 540 & 406 & 333 & 180 & 111 \\
\hline \multicolumn{11}{|c|}{ Constant $i r=415$} \\
\hline Verbal & .204 & .077 & .026 & .054 & .129 & .163 & & & & \\
\hline Quantitative & .239 & .191 & .160 & .103 & .254 & .279 & & & & \\
\hline Advanced & .244 & .224 & .182 & .132 & .347 & .292 & & & & \\
\hline
\end{tabular}


grades than with freshman grades. In spite of the advantage the common metric gives to the correlation with first-year graduate grades, the correlations with the quantitative test are approximately of the same size. Even though the GRE tests are administered in the senior year, their correlations with freshman grades are as high or higher than the correlations with firstyear graduate grades. It does seem highly probable, however, that predictions of graduate grades are higher than concurrent correlations with senior grades. Seemingly the first graduate year and the freshman year have something in common not shared with the senior year.

In contrast to the three graduate departments, the law school required applicants to submit the Law School Aptitude Test (LSAT) as well as undergraduate transcripts. This information was combined linearly and admission decisions were based on the composite. Table 5 contains the correlations for both the overall aptitude score and the writing ability score for maximum and constant $N$ s.

The most obvious finding here is the low level, including small negative values, of the correlations between the LSAT and undergraduate grades. As described above, a compensatory selection system with a relatively high cutoff was used. The expected result is the bias in the correlations. The Aptitude score of the LSAT was given greater weight than Writing Ability so there would be greater bias in the former correlations. Even so, there is a very small tendency for the correlations to be higher positive or smaller negative with freshman grades than with junior and senior grades. (Without the expectation based on other data sets, this tendency would not merit comment.)

First-year law school grades are somewhat more predictable than third year grades. While the differences are not large, the trend is more impressive if one looks at the odd and even numbered semesters as separate sets. It is tempting to assume that, without the compensatory selection system, the gradient of validities that presumably started with the undergraduate freshman year is reaching an asymptote. This gradient of validities is, therefore, congruent with the interpretation of the intercorrelations of law school grades over the total seven-year period: namely, that the correlations form a single simplex matrix.

\section{Discussion}

Before attempting to discuss further the

Table 5

Validities of the Two LSAT Tests and Undergraduate and Graduate Averages Computec in Two Different Ways

\begin{tabular}{|c|c|c|c|c|c|c|c|c|c|c|}
\hline \multirow{2}{*}{ Group \& Test } & \multicolumn{3}{|c|}{ Undergraduate } & Year & \multicolumn{6}{|c|}{ Graciuate Semester } \\
\hline & 1 & 2 & 3 & 4 & 1 & 2 & 3 & 4 & 5 & 6 \\
\hline \multicolumn{11}{|l|}{ Total Sample } \\
\hline Aptituce & $\begin{array}{l}.021 \\
1159\end{array}$ & $\begin{array}{l}.021 \\
1165\end{array}$ & $\begin{array}{r}.022 \\
1166\end{array}$ & $\begin{array}{r}-.031 \\
1129\end{array}$ & $\begin{array}{l}.267 \\
1228\end{array}$ & $\begin{array}{r}292 \\
1227\end{array}$ & $\begin{array}{l}226 \\
1060\end{array}$ & $\begin{array}{r}250 \\
1056\end{array}$ & $\begin{array}{r}.156 \\
879\end{array}$ & $\begin{array}{r}.212 \\
753\end{array}$ \\
\hline Writing Ability & .151 & .102 & .071 & .029 & .192 & .162 & .155 & .155 & .099 & .084 \\
\hline in & 1159 & 1165 & 1166 & 1129 & 1228 & 1227 & 1060 & 1056 & 879 & 752 \\
\hline \multicolumn{11}{|l|}{ Constant $\mathrm{N}=674$} \\
\hline Aptitude & -.147 &. .148 & -.199 & -.147 & .225 & .251 & .189 & .214 & .152 & .211 \\
\hline Writing Ability & .086 & .012 & -.026 & -.038 & .146 & .105 & .101 & .103 & .093 & .092 \\
\hline
\end{tabular}


meaning of these data, it will be desirable to recapitulate the findings to date:

(1). Independently computed undergraduate grade-point averages show a quasi-simplex pattern of intercorrelations. Data in the current report indicate that this pattern is general over many institutions. The pattern is also very similar for pre-law students and students preparing for entrance into graduate departments of chemistry, physics, and mathematics.

(2). Independently computed graduate and professional school GPAs also show the quasisimplex form over a period of six semesters. There is seemingly more change from the first to the sixth semester in the graduate departments than in the law school, but third-year grades in the former departments may not be as reliable as earlier grades.

(3). When an allowance is made for the attenuation in correlations produced by the lack of a common metric for grades in the many undergraduate institutions represented, the simplex pattern is continuous from the first undergraduate year to the third professional school year in the law school.

(4). Correlations between undergraduate and graduate grades are also attenuated by the lack of a common metric for the former, but there is no evidence that senior grades predict grades in the graduate departments more accurately than freshman grades. In other words, the simplex pattern is not continuous. There is a break at the beginning of graduate school.

(5). Aptitude tests given both predictively and postdictively show very similar gradients of correlations with undergraduate and graduate grades. Correlations decrease in size monotonically from the freshman through the senior year and from the first through the third post-baccalaureate year. The undergraduate gradient is less obvious for law school students because they were selected by means of a compensatory system that also involved a high cutoff. As a result, correlations with the selection tests are either very low or somewhat negative.

(6). The advanced test in the discipline for graduate students shows a flatter gradient of correlations with undergraduate grades, but senior grades still have a lower correlation with the achievement test than do freshman grades.

(7). In the graduate departments the advanced test is probably more highly correlated with first-year graduate grades than with senior grades. The level of correlation with firstyear graduate grades, furthermore, may be at about the same level as those with freshman grades. More definitive statements cannot be made because the lack of a common metric for undergraduate grades makes these conclusions matters of judgment rather than statistical analysis.

Each study in this series has made it more difficult to tie together the various findings. Data do destroy attractive hypotheses, and data that are dependable from the sampling point of view allow one to discard hypotheses with confidence. The glib assertion in 1968 that people are changing was clearly not sufficient in 1972 . The hypothesis, derived from the postdiction results, that broad abilities change little at the college level but that narrow abilities or skills are being acquired must also be modified substantially. On the basis of this hypothesis, evidence for a continuous simplex matrix extending over a period of seven years should have been found for the graduate students. Such evidence should have been less marked or nonexistent for the professional students in the law school. Yet evidence for the continuity of the process or processes underlying the simplex matrix was obtained in the law school but not in the graduate departments.

If the larger break occurs between undergraduate and graduate school with a smaller or nonexistent break between undergraduate and law school, a reasonable hypothesis points to methods of instruction rather than to content. 
Law school courses are more similar to undergraduate courses than are the courses and laboratories in graduate school. Both the goals of instruction and the requirements placed upon the students differ in law school and graduate school.

Predictive correlations with the selection tests do not become negative in any data set. There is a common core of variance in grades that continues to be associated with test scores. Also, if correlations with first-year graduate and professional school grades are indeed higher than with senior grades - the problem of metric requires a solution before any more definitive statement can be made-a plausible interpretation is one phrased in terms of intellectual challenge. The freshman year is seemingly more challenging intellectually than the senior year, and the first graduate or professional year constitutes a new challenge. After each of these beginnings, students learn to accommodate to the system. The bar examination for law school students should, according to this view, constitute a new challenge leading to a larger intellectual component in the scores on that examination. ${ }^{3}$ Perhaps the first position subsequent to the Ph.D. would have similar characteristics for the graduate students.

${ }^{3}$ Carison and Werts in their unpublished study have data on bar examination results. The LSAT has about equal correlations with the bar examination and first year law school grades. Both have lower correlations with third year grades.

\section{References}

Carlson, A. B., \& Werts, C. E. Relationships among law school predictors. law school performance and bar examination results. Princeton, N.J.: Educational Testing Service, Draft, October 1975.

Humphreys, L. G. Investigations of the simplex. Psychometrika, 1960, 25, 313-323.

Humphreys, L. G. The fleeting nature of the prediction of college academic success. Journal of Educational Psychology, 1968, 59, 375-380.

Humphreys, L. G., \& Taber, T. Postdiction study of the GRE and eight semesters of college grades. Journal of Educational Measurement, 1973, 10. 179-184.

Humphreys, L. G., Levy, J., \& Taber, T. Predictability of academic grades for students of high and low academic promise. Educational and Psychological Measurement. 1973, 33, 385-392.

Lin, P. C. An investigation of the prediction of advanced academic performance. Unpublished dissertation, University of Illinois, Urbana-Champaign, 1976.

Lunneborg, C. E., \& Lunneborg, P. W. Relations between aptitude changes and academic success during college. Journal of Educational Psychology, $1970,61,169-173$.

\section{Acknowledgements}

This paper is based upon a dissertation submitted to the Graduate College, University of Illinois, Urbana-Champaign, by Dr. Lin. The research was supported by a research grant, Prediction of Advanced Academic Performance, $M H$ 23612.01 and $M H$ 23612-02, National Institute of Mental Health. The authors wish to thank Mrs. Evelyn Llacuna for her assistance in gathering data.

\section{Authors' Addresses}

Pang-chieh Lin, National Chengehi University, Tdiwan, Republic of China. Lloyd G. Humphreys, Department of Psychology, University of Illinois, Champaign IL 61820. 